\title{
Cultural Values And Leadership Behavior In The United States, Jamaica, And The Bahamas
}

Doreen J. Gooden (E-mail: gooden@ huizenga.nova.edu), Nova Southeastern University Robert C. Preziosi (E-mail: preziosi@ huizenga.nova.edu), Nova Southeastern University

\begin{abstract}
As global companies access business opportunities in other countries, culture and leadership practices become critical issues. Thus, it was timely that this study examined the effects of national culture on leadership behavior of Americans, Jamaicans, and Bahamians. These countries were chosen because of Jamaica's and the Bahamas strong relationship with the United States (economic interdependence).

MBA students attending classes in these countries and holding leadership positions within their respective organizations participated in the study. The results in addition to confirming other cross-cultural researchers' work that the values and attitudes of individuals vary from country, also identifies that there are differences in leadership behavior across countries.
\end{abstract}

\section{Introduction}

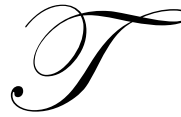

he challenge of globalization has heightened the awareness and study of cultural issues. Research suggests that culture can influence leadership concepts (House, Wright \& Aditya, 1997). Thus, the study of cross-cultural leadership in understanding what makes people of different cultures behave the way they do will help managers gain the respect and influence needed to develop effective leadership skills and practices.

This study addresses the following questions:

- $\quad$ Are the values and attitudes of the organizational leaders from countries in the study different?

- Does transformational leadership differ across countries? If so, how?

\section{Review Of Related Literature}

\subsection{Hofstede's Cultural Dimensions}

Hofstede's $(1980,2001)$ seminal study on national culture has been widely used in cross-cultural study. In the 1970's Hofstede conducted a study with a group of IBM Corporation employees working in over fifty national subsidiaries but of the same multinational business corporation. Hofstede sought to compare the values and attitudes of respondents in one country with the values and attitudes of respondents in another country. Based on his analysis, he found that the scores within specific groups of questions were inter-related and, thus, he classified them as "dimensions" of culture.

The following dimensions were identified from his study:

- $\quad$ Power Distance

- Individualism/Collectivism 
- $\quad$ Masculinity/Femininity

- Uncertainty Avoidance

A fifth dimension, long-term versus short-term orientation, (a part of Confucian Dynamism) was later added, based on a study conducted by Michael Bond, using the Chinese Values Survey (CVS) Hofstede (2001). The long-term versus short-term dimension will not be discussed in this research.

\subsection{Power Distance}

Hofstede (2001) theorized "power distance is the extent to which a society accepts that power is distributed equally in institutions and organizations" (pg. 83). Hofstede argued that inequality exists between a less powerful and a more powerful person.

In an organization, power distance is reflected in superior-subordinate relationships. Hofstede found that superiors in high power distance societies are more autocratic in their leadership style, more task oriented, and less people oriented. Also, subordinates tend to be submissive to their superiors. In low power distance societies, superiors are more participative and consultative.

\subsection{Individualism/Collectivism}

Individualism refers to a society in which people are expected to take care of themselves and their immediate family. The people in this type of culture value individual accomplishment. They are self-seeking and they work toward their personal goals, which receive priority over group goals.

Individualism is in contrast to collectivism. Hofstede (2001) referred to persons in a collectivist society as having a tight social framework where there is a distinction between the in-group and the out-group. The in-group refers to relatives, clans or organizations and it is expected that the in-group will look after them in exchange for loyalty.

\subsection{Uncertainty Avoidance}

Uncertainty Avoidance refers to how a society responds to threatening, ambiguous and uncertain situations. According to Hofstede (2001), individuals try to avoid these situations by seeking career stability, creating more formal structures and rules, avoiding unrealistic ideas and behaviors, and striving for absolute truth and expertise. Societies high in uncertainty avoidance prefer a clear task and management structure, and, therefore, rules and regulations are instituted to ensure predictability in the organization.

\subsection{Masculinity/Femininity}

Masculinity refers to the extent to which a society is 'Masculine' - that is, the assertiveness, the acquisition of money and things, and not caring for others. Femininity refers to a more cooperative society, where there is a more 'tender' approach to dealing with people, more caring, pleasant co-workers and good working conditions. Emphasis is on the quality of life or people (Hofstede 2001).

\subsection{Transformational Leadership}

Transformational leadership was conceptualized by Burns (1987) as a result of conducting studies on political leaders. He contends that transformational leadership is a reciprocal process between leaders and their followers. Here the leaders have the ability to raise the consciousness of their subordinates and to influence their behaviors. These leaders will also empower their subordinates. This enables them to participate in transforming the organization. Thus, according to Bass (1985), this reciprocal process has the potential to change social systems and reform political institutions. Bass (1985) developed on Burns (1978) transformational leadership and integrated organizational psychology with political science. 


\subsection{Transformational Leadership And National Culture}

According to Gerstner and Day (1994), leadership perceptions differ across countries. Brodbeck et al. (2000) note that there are cultural differences in the way people perceive and think about outstanding leadership in Europe. Shaw (1990) addressed the issue of pre-existing leader prototypes and argued that the leader prototype that is "stored in the memories" of subordinates in a host-country might be different with that of the expatriate manager. Pillai, Scandura and Williams (1999) examined leadership patterns across cultures and found that there were strong similarities within western cultures and differences between western and non-western cultures. Yousef (2000) found that national culture moderates the relationship of leadership behavior with job satisfaction.

Robert et al. (2000) in their study examining the management practices in India, Mexico, Poland and the United States, found that empowerment across the countries was different. U.S., Mexican, and Polish employees had a favorable view of their supervisors when empowerment was high, whereas Indian employees rated their supervisors low when empowerment was high. Pelled and Zin (1997) suggest that the low power distance culture of the U.S. makes vertical job involvement more accepting and appropriate to U.S. workers, while in high power cultures like Mexico and China where individuals are accustomed to differences in class and authority, vertical job involvement is not welcomed. This reinforces the point of many cross-cultural researchers that some western management concepts might not necessarily work abroad. Additionally, Jung and Avolio (1999) found that subordinates of different cultures could interpret leader behaviors and statements differently.

Jung, Bass, and Sosik (1995) posit that in collectivistic cultures, transformational leadership is more evident than in individualistic cultures. Newman and Nollen (1996) also found that in cultures high on individualism, performance was high when managers placed emphasis on individual employee contribution. In the collectivist culture, performance was higher in work units that placed less emphasis on individual employee contribution.

Den Hartog et al. (1999) found that in feminine cultures leaders use a more consultative approach, whereas leaders in masculine cultures have a more direct and aggressive approach. Newman and Nollen (1996) found that in masculine cultures work unit performance was higher if management used merit-based rewards for pay and promotion. Opportunities for earning, advancement, and cooperative colleagues are related to masculinity (Singh 1990). In feminine cultures, work units performed at a higher level when management reduced its usage of meritbased rewards.

Offerman and Hellman (1997) examined the relationship of work-related values of managers in 39 different countries and their leadership styles as perceived by their subordinates and found that power distance was significantly and negatively associated with leader communication, approachability, and team building. Hofstede (2001) noted that subordinates in high power distance societies will expect superiors to be autocratic and in low power distance societies that supervisors will consult them in the decision making process. Singh (1990) found that variations in power distance were related to preferred and perceived style of the superior.

In countries where there is high uncertainty, CEOs are greatly involved in strategic planning (Koufopoulos and Chryssochoidis, 2000). This suggests that lower level employees might not be included in the strategic planning process. Offerman and Hellman (1997) found that uncertainty avoidance was significantly associated with more leader control, but less with delegation and approachability. Jung, Bass, and Sosik (1995) concluded that in high uncertainty avoidance cultures leaders are subject to rules and procedures. They also found that leaders in low uncertainty countries are expected to be more innovative than leaders in high uncertainty avoidance countries. Leaders in a country low on uncertainty avoidance are, therefore, more likely to take risk. However, Den Hartog et al. (1999), found that risk taking is not necessarily seen as contributing to outstanding leadership when examined at a universal level. Variations in uncertainty avoidance are related to stress at work and employment stability (Singh 1990).

Mukherji and Hurtado (2001) indicated that because of the decisive nature of individualist planners, they prefer situations in the environment which are analyzable and which can be under the control of an organization. Nakata and Sivakumar (1996) found that persons in individualistic societies are more likely to support the initiation 
of new product development while the collectivists are more likely to support the implementation process. Triandis (1993) positioned that achievement motivation is socially oriented among collectivists and individually oriented among individualists. His explanation is that many individualists have a false sense of uniqueness and this motivates individuals to prove themselves as having socially desirable attributes thereby forcing them to exhibit high personal achievement.

In an individualistic society, support is valued when needed, but dominant leader behaviors including achievement-oriented and participative leadership would be exhibited. Triandis (1982) posits that leaders who are perceived as ingroup members are able to lead enthusiastic followers, while if they are perceived as outgroup members they are likely to be undermined by their followers. In a further study Triandis, et al. (1990), identified that collectivists are more prevalent in ethnic groups, where they are seen more as close to their in-groups and far from their out-groups.

\section{Methodology}

\subsection{Sample Population}

Two hundred and thirty five students, pursuing their Masters of Business Administration Degree at an American university with student learning centers in Jamaica, Bahamas, and Fort Lauderdale (USA) were asked to participate in the study. This population was chosen because of ease of access. Only those participants who stated their nationality as being one of the countries in the study and with no change from birth were included in the data analysis. Additionally, only those students who held leadership positions in their respective organizations were considered. These included professionals and individuals who manage one or more subordinates.

Two instruments were used for this study - Hofstede's (1994) Values Survey (VSM) and Bass (1985) Multifactor Leadership Questionnaire (MLQ5X).

Hofstede's (1994) Values Survey Module (VSM) was used to compare the values and attitudes of participants of each country in the study. The questionnaire consists of twenty content questions and six sociodemographic questions.

\begin{tabular}{|l|l|}
\hline Power Distance(PDI) & $-35 \mathrm{~m}(03)+35 \mathrm{~m}(06)+25 \mathrm{~m}(14)-20 \mathrm{~m}(17)-20$ \\
\hline Individualism (IDV) & $-50 \mathrm{~m}(01)+30 \mathrm{~m}(02)+20 \mathrm{~m}(04)-25 \mathrm{~m}(08)+130$ \\
\hline Masculinity (MAS) & $+60 \mathrm{~m}(05)-20 \mathrm{~m}(07)+20 \mathrm{~m}(15)-70 \mathrm{~m}(20)+100$ \\
\hline Uncertainty Avoidance (UAI) & $+25 \mathrm{~m}(13)+20 \mathrm{~m}(16)-50 \mathrm{~m}(18)-15 \mathrm{~m}(19)+120$ \\
\hline
\end{tabular}

In the formulas above, $\mathrm{m}(03)$ is the mean score for question $3, \mathrm{~m}(06)$ is the mean score for question 6 , etc. The VSM 94 manual indicates that the indices should have a value between 0 and 100, but values below 0 and above 100 are technically possible. A five-point Likert scale was used for item responses:

- Questions 1 to $12 \quad$ - responses ranging from $1=$ of utmost importance to 5 of very little or no impotance

- Questions 13 and 14 - responses ranging from 1= never to 5= always

- $\quad$ Questions 15 to 20 - responses ranging from $1=$ strongly agree to $5=$ strongly disagree

Bass and Avolio's (1985) Multifactor Leadership Questionnaire (MLQ5x) was used to assess the transformational leadership. The following twenty questions examined transformational leadership:

Questions 2,6,8,9,10,13,14,15,18,19,21,23,25,26,29,30,31,32,34,36.

The MLQ5x instrument uses a five-point Likert scale with values as follows: $0=$ not at all, $1=$ once in a while, 2 = sometimes, 3 = fairly often, 4 = frequently or always. Lower scores indicate that leaders' behaviors are inconsistent with leadership factors and in the converse, higher scores indicate that leaders' behaviors are consistent with leadership factors. 


\subsection{Hypotheses}

H0: The values and attitudes of organizational leaders from the countries in the study are not different.

H1: The values and attitudes of organizational leaders from the countries in the study are different.

$\mathbf{H O}^{2}$ : Transformational leadership practices do not differ between countries.

H1 $^{2}$ : Transformational Leadership practices differ between countries.

\section{Results}

Table 1 provides a breakdown of respondents by gender and nationality. Data indicates that females were $66 \%$ of the respondents and males were $34 \%$ of the respondents. When gender was examined by country, of the 62 Jamaicans, 18 (29\%) were male, and 44 (71\%) female; of the 68 Bahamians, 18 (26\%) were male, and 50(74\%) female; and of the 105 Americans, 44 (42\%) were male and 61 (58\%) female.

\section{Table 1: Gender And Nationality}

\begin{tabular}{|lll|r|r|r|r|}
\hline & & \multicolumn{3}{|c|}{ NATIONALITY } & \multirow{2}{*}{ Total } \\
\cline { 3 - 6 } & & Jamaican & Bahamian & American & \multicolumn{1}{c|}{80} \\
\hline GENDER & male & Count & 18 & 18 & 44 & 80 \\
& & $\%$ within NATIONAL & $29.0 \%$ & $26.5 \%$ & $41.9 \%$ & $34.0 \%$ \\
\cline { 2 - 6 } & female & Count & 44 & 50 & 61 & 155 \\
& & $\%$ within NATIONAL & $71.0 \%$ & $73.5 \%$ & $58.1 \%$ & $66.0 \%$ \\
\hline Total & & Count & 62 & 68 & 105 & 235 \\
& & $\%$ within NATIONAL & $100.0 \%$ & $100.0 \%$ & $100.0 \%$ & $100.0 \%$ \\
\hline
\end{tabular}

Table 2 provides data on age distribution by nationality. Eighteen persons $(7.7 \%)$ were in the age group 20-24; fifty-one persons (21.7\%) were in the age group 25-29; fifty-five persons (23.4\%) in the age group 30-34; fifty persons (21.3\%) were in the age groups 35-39 and 40-49, and eleven persons (4.7\%) in the age group 50-59.

Table 2: Age And Nationality

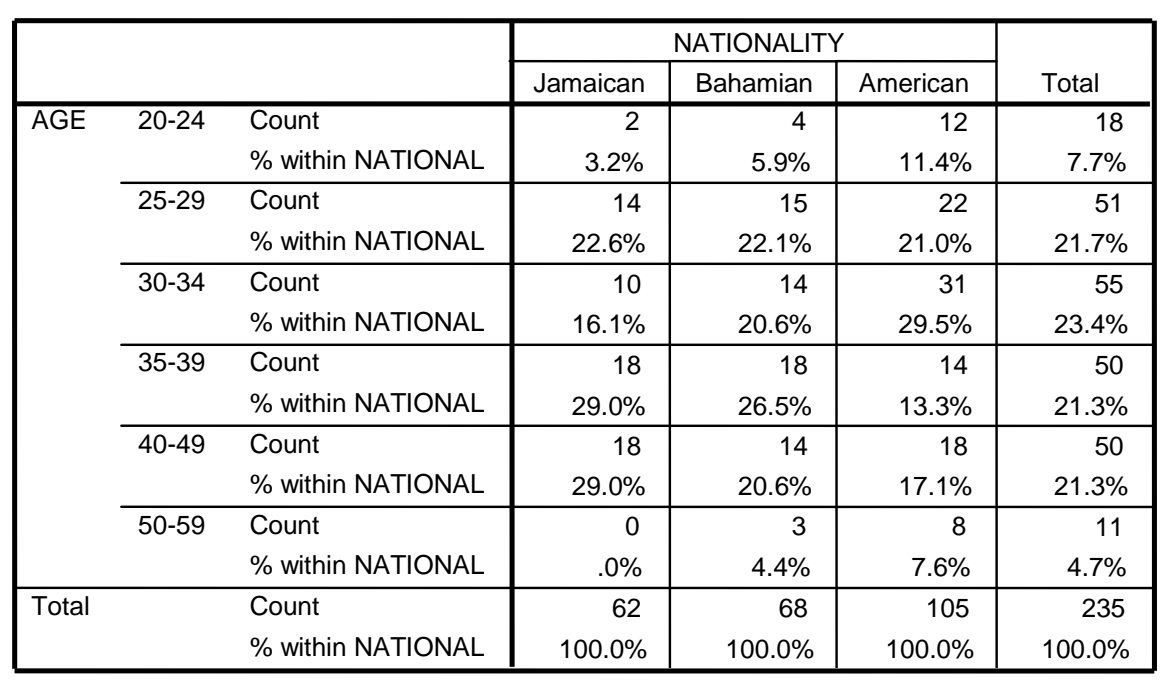


Pearson Chi-Square tests were conducted to determine if there were differences in respect to gender and age across the three countries. There were statistically significant differences in gender and age across the countries. For gender $\left.\chi^{2}=23.936, p=.000\right)$; and for age $\left(\chi^{2}=47.664, p=.000\right)$.

Tables 3 to 6 present results for hypothesis 1 :

H0: The values and attitudes of organizational leaders from the countries in the study are not different from each other.

H1: The values and attitudes of organizational leaders from the countries in the study are different from each other.

Based on the central limit theorem and previous work done by Fernandez et al. (1997), this study used standardized scores to compare the rankings with Hofstede's study. Fernandez et al. (1997) methodology is, therefore, adapted in the computation and illustration of the results. Mean scores for each country in this study and Hofstede's study are presented. The overall mean scores and standard deviations presented in Hofstede's computation are based on the mean scores and standard deviation of all 50 countries and three regions in his study. The Bahamas was not included in Hofstede's study.

Table 3 examines Power Distance and this table is used to illustrate the results. In Hofstede's $(1980,2001)$ study, the United States had a country score of 40 for power distance, the overall mean for all countries was 57 and the standard deviation was 22. Based on Hofstede's study, The United States' standardized score is, therefore, (40$57) / 22$ ) or -0.77 . The standardized score is negative and less than one, suggesting that the country is less than one standard deviation below the mean for the sample.

In the present study, The United States had a raw score of 28 , the overall mean for all countries was 32, and the standard deviation was 7.81. The standardized score for the power distance dimension in this study is, therefore, (28-32)/7.81 or -0.51 . As in Hofstede's case, the score is negative and less than one, suggesting that the United States is less than one standard deviation below the mean for the sample.

When the two standardized scores are compared, very little movement in ranking is seen between this study and that of Hofstede's. The United States remains a low power distance country.

The highest raw score was 41 , which indicates that the Bahamas is higher on power distance than the other countries. The lowest raw score was 27, indicating that Jamaica is lower on power distance than the other countries. The highest standardized score of 1.15 indicates that the Bahamas is higher on the average for power distance. Lower standardized scores (-0.64), indicate that Jamaica is lower on the average for power distance.

In Hofstede's study, the United States and Jamaica were low in power distance. This study confirms Hofstede's findings in respect to the United States and Jamaica for power distance, although there were very slight movements.

Table 3: Power Distance

\begin{tabular}{|lcccr|}
\hline & \multicolumn{2}{c}{ Hofstede (1980, 2001) } & \multicolumn{2}{c|}{ Current Study (2003) } \\
Country & Raw & Standardized & Raw & Standardized \\
\hline Jamaica & 45 & -0.55 & 27 & -0.64 \\
Bahamas & & & 41 & 1.15 \\
United States & 40 & -0.77 & 28 & -0.51 \\
\hline \multicolumn{1}{|c}{ Overall } & & Overall & \\
Mean & 57 & Mean & 32.00 \\
Std. Dev. & 22 & Std. Dev. & 7.81 \\
\hline
\end{tabular}




\section{Individualism}

In the present study, Jamaica and the United States are seen as high on individualism. The Bahamas is low on individualism. In Hofstede's study the United States was high on individualism and Jamaica was low on individualism. There was significant movement with Jamaica moving from a collectivist society to a highly individualist society. These results are reported in Table 4.

Table 4: Individualism

\begin{tabular}{|lcccc|}
\hline & \multicolumn{2}{c}{ Hofstede (1980, 2001) } & \multicolumn{2}{c|}{ Current Study (2003) } \\
Country & Raw & Standardized & Raw & Standardized \\
\hline Jamaica & 39 & -0.16 & 100 & 1.05 \\
Bahamas & & & 92 & -0.07 \\
United States & 91 & 1.92 & 95 & 0.35 \\
\hline \multicolumn{1}{|c}{ Overall } & & Overall & \\
Mean & 43 & Mean & 95.67 \\
Std. Dev. & 25 & Std. Dev. & 4.04 \\
\hline
\end{tabular}

\section{Masculinity}

In the present study, only the United States can be classified as a highly masculine country. The other two countries are low in masculinity with Bahamas being the lowest. In Hofstede's study, Jamaica and the United States were considered masculine countries. So, there is a shift in Jamaica from being a masculine country to a feminine one. These results are reported in Table 5.

Table 5: Masculinity

\begin{tabular}{|lcccc|}
\hline & \multicolumn{2}{c}{ Hofstede (1980, 2001) } & \multicolumn{2}{c|}{ Current Study (2003) } \\
Country & Raw & Standardized & 17 & Saw \\
\hline Jamaica & 68 & 1.06 & 8 & -0.24 \\
Bahamas & & & 42 & -0.84 \\
United States & 62 & 0.72 & & 1.45 \\
\hline \multicolumn{1}{|c|}{ Overall } & & Overall & 16.75 & \\
Mean & 49 & Mean & 17.62 & \\
Std. Dev. & 18 & Std. Dev. & & \\
\hline
\end{tabular}

\section{Uncertainty Avoidance}

In this study, Jamaica, Bahamas, and the United States are classified as countries with weak uncertainty avoidance. These results are similar to Hofstede's study. The results are reported in Table 6.

Table 6: Uncertainty Avoidance

\begin{tabular}{|lcccc|}
\hline & \multicolumn{2}{c}{ Hofstede (1980, 2001) } & \multicolumn{2}{c|}{ Current Study (2003) } \\
Country & Raw & Standardized & Raw & Standardized \\
\hline Jamaica & 13 & -2.17 & 23 & -1.01 \\
Bahamas & & & 29 & -0.11 \\
United States & 46 & -0.79 & 28 & -0.26 \\
\hline \multicolumn{1}{|c}{ Overall } & & Overall & \\
Mean & 65 & Mean & 26.67 \\
Std. Dev. & 24 & Std. Dev. & 3.21 \\
\hline
\end{tabular}


The reliability score for transformational leader was .8385 , which is at an acceptable level as it exceeds the standard cut-offs for internal consistencies (Cronbach 1951).

The data in Table 7 provides support for hypothesis 2 :

$\mathbf{H O}^{2}$ : Transformational leadership does not differ between countries.

H12: Transformational Leadership differs between countries.

Table 7 presents the mean scores and standard deviations of transformational leadership practices in each of the three countries in the study.

\section{Table 7: Mean Scores For Transformational Leadership}

TRANLEAD

\begin{tabular}{|l|r|r|r|}
\hline NATIONAL & Mean & \multicolumn{1}{|c|}{$\mathrm{N}$} & Std. Deviation \\
\hline Jamaican & 3.1668 & 62 & .41457 \\
Bahamian & 3.2060 & 68 & .40897 \\
American & 3.0019 & 105 & .45877 \\
Total & 3.1045 & 235 & .44157 \\
\hline
\end{tabular}

The Bahamas, a collectivist society, scored higher in transformational leadership than the other two countries. This confirms (Jung, Bass, and Sosik 1995) findings that in collectivistic cultures, transformational leadership is more evident than in individualistic cultures.

The ANOVA results, reported in table 8 show a $\mathrm{F}$ value of $5.448, \mathrm{p}=.005$, suggesting that transformational leadership differs between countries. A Bonferroni post hoc test presented in table 9 was done to determine the actual differences. There were differences between Bahamians and American.

Table 8: ANOVA

TRANLEAD

\begin{tabular}{|l|r|r|r|r|r|}
\hline & \multicolumn{1}{|c|}{$\begin{array}{c}\text { Sum of } \\
\text { Squares }\end{array}$} & \multicolumn{1}{c|}{$\mathrm{df}$} & Mean Square & $\mathrm{F}$ & Sig. \\
\hline Between Groups & 2.047 & 2 & 1.023 & 5.448 & .005 \\
Within Groups & 43.579 & 232 & .188 & & \\
Total & 45.626 & 234 & & & \\
\hline
\end{tabular}




\section{Table 9: Multiple Comparisons}

$\begin{aligned} & \text { Dependent Variable: TRANLEAD } \\
& \text { Bonferroni }\end{aligned}$
\begin{tabular}{|ll|c|r|r|r|r|}
\hline \multirow{4}{*}{} & & & & & \\
(I) NATIONAL & $(\mathrm{J})$ NATIONAL & $\begin{array}{c}\text { Mean } \\
\text { Difference } \\
\text { (I-J) }\end{array}$ & Std. Error & Sig. & Lower Bound & Upper Bound \\
\hline Jamaican & Bahamian & -.0393 & .07611 & 1.000 & -.2228 & .1443 \\
& American & .1649 & .06942 & .055 & -.0025 & .3323 \\
\hline Bahamian & Jamaican & .0393 & .07611 & 1.000 & -.1443 & .2228 \\
& American & $.2041^{*}$ & .06746 & .008 & .0414 & .3668 \\
\hline American & Jamaican & -.1649 & .06942 & .055 & -.3323 & .0025 \\
& Bahamian & $-.2041^{*}$ & .06746 & .008 & -.3668 & -.0414 \\
\hline
\end{tabular}

${ }^{*}$. The mean difference is significant at the .05 level.

\section{Conclusions}

The first research question explored whether the values and attitudes of the participants from the countries in the study were different. The results demonstrate that there are differences in the values and attitudes of individuals across the three countries.

Hofstede's theory was largely confirmed except for Jamaica moving to a highly individualistic and feminine society. The Bahamas was identified as a high power distance, low uncertainty avoidance, feminine, and collectivist society. Jamaica was identified as a low power distance, low uncertainty avoidance, feminine, and individualistic society. The United States was identified as a low power distance, low uncertainty avoidance, masculine, and individualistic society.

The second research question explored whether transformational leadership differs across countries. Differences were found between the Americans and the Bahamians. The Americans and the Bahamians were only similar in respect to low uncertainty avoidance cultural dimension. Thus, it is not surprising that there would be differences in transformational leadership behavior. The findings clearly support the point that leaders' practices will be constrained by the cultural orientation of their followers. Therefore, leaders' practices should be compatible with the society in which he/she operates.

There were certain limitations of the study. The number of countries in the study was below the recommended 10 for cross-cultural studies. A larger number of countries would lead to greater generalizability of the study. Also, the sample population was comprised of students from a western university with established cluster sites in the countries of the study. The leadership questionnaire measures western concepts and, therefore, there could be concerns that the results could be due to the influence of western concepts taught in a western university.

Another concern is that the sample population was predominantly female and that could influence the results particularly as it relates to the masculinity index.

Also, the survey was conducted amongst MBA students who hold leadership positions in their organizations. Therefore, the results could be reflective of the values and attitudes of that group and perhaps not generalizable to the broader societies.

The researcher recommends that further research be done at all stratum of the society to provide a more meaningful and robust generalization to findings relating to the values and attitudes of each society. 
Secondly, further studies could be conducted to determine the subordinates' views of their leaders' practices in the respective countries.

Thirdly, future research could be conducted to examine leadership practices in different organizations within each country and to identify the differences in these leadership practices across organizations.

\section{References}

1. Avolio, B.J. Bass, B.M. and Jung, D.I. (1995). MLQ: Multifactor leadership questionnaire. Redwood City. CA: Mind Garden, Inc.

2. $\quad$ Bass, B.M. (2000). "The future of leadership in organizations", Journal of Leadership Studies, 7 (3), 18-40.

3. Bass, B.M. (1985). Leadership and performance beyond expectations, New York, Free Press.

4. Bass, B.M., and Avolio, B. (1993). "Transformational leadership and organizational culture", PAQ, 112121.

5. Black, B. (2001). "Culturally coded? The engima of flexible labour markets", Employee Relations, 23 (4/5), 401-416.

6. Brodbeck, F., et al. (2000). "Cultural variation of leadership prototypes across 22 European countries", Journal of Occupational and Organizational Psychology, 73 (1) 1-29.

7. $\quad$ Burns, J.M., (1978). Leadership, New York, NY: Harper \& Row Publishers, Inc.

8. Cronbach, L.J. (1951). "Coefficient alpha and internal structure of tests", Psychometrika, 16, 297-334.

9. Den Hartog et al (1999). "Culture specific and cross-culturally generalizable implicit leadership theories: Are attributes of charismatic/transformational leadership universally endorsed?", Leadership Quarterly, 10 (2), 219-256.

10. Fernandez, D. et al. (1997). "Hofstede's country classification 25 years later", The Journal of Social Psychology, 137, 43-55.

11. Gerstner, D., and Day, D. (1994). "Cross-cultural comparison of leadership prototypes", Leadership Quarterly, 5 (2), 121-134.

12. Hofstede, G. (1994). Values survey module manual (VSM94). Tilburg University, The Netherlands.

13. Hofstede, G. (2001). Culture's Consequences. $\left(2^{\text {nd }}\right.$. Ed). Thousand Oaks, California. Sage Publications.

14. House, R.J., Wright, N.S., and Aditya, R.N. (1997). "Cross cultural research on organizational leadership: A critical analysis and a proposed theory", in P.C. Early and M. Erez (eds.) New Perspectives In International Industrial Organizational Psychology. San Francisco: New Lexington.

15. Jung, D., and Sossik, J. (2002). "Work-group characteristics and performance in collectivistic and individualistic cultures", The Journal of Social Psychology, 142 (1) 5-23.

16. Koufopoulos, D.N., and Chryssochoidis, G.M. (2000). "The effects of an uncertain country environment upon leadership and strategic planning practices", Strategic Change, 9, 379-395.

17. Mukherji, A., and Hurtado, P. (2001). "Interpreting, categorizing and responding to the environment: The role of culture in strategic problem definition", Management Decision, 39 (2), 105-112.

18. Nakata, C., and Sivakumar, K. (1996). "National culture and new product development: An integrative review", Journal of Marketing, 60 (1), 61-71.

19. Newman, K., and Nollen, S. (1996). "Culture and congruence: the fit between management practices and national culture", Journal of International Business, 27 (4), 753-780.

20. Offerman, L., and Hellman, P. (1997). "Culture's consequences for leadership behavior - National values in action”, Journal of Cross-Cultural Psychology, 28 (3), 342-351.

21. Pelled, L. and Xin, K. (1997). "Work values and their human resource management implications: A theoretical comparison of China, Mexico, and the United States", Journal of Applied Management Studies, $6(2), 185-198$.

22. Pillai, R., Scandura, T., and Williams E. (1999). "Leadership and organizational justice: Similarities and differences across cultures”, Journal of International Business Studies, 39 (4), 763-779.

23. Robert, C. et al. (2000). "Empowerment and continuous improvement in the United States, Mexico, Poland, and India: Predicting fit on the basis of the dimensions of power distance and individualism", Journal of Applied Psychology, 85 (5), 643-658. 
24. Singh, J. (1990). "Managerial culture and work-related values in India", Organization Studies, 11 (1), 75-101.

25. Triandis, H. (2001). "The study of cross cultural management and organization: The future", Journal of Cross Cultural Management, 1(1), 17-20.

26. Triandis, H. (1982). "Dimensions of cultural variation as parameters of organizational theories", International Studies of Management \& Organization, 12 (4), 139-169.

27. Yousef, D. (2000). "Organizational commitment: A mediator of the relationships of leadership behavior with job satisfaction and performance in a non-western country", Journal of Managerial Psychology, 15 (1), 6-24.

Notes 
Notes 